\title{
NKp46 defines ovine cells that have characteristics corresponding to NK cells
}

\author{
Timothy Connelley ${ }^{1 *}$, Anne K Storset ${ }^{2}$, Alan Pemberton ${ }^{1}$, Niall MacHugh', Jeremy Brown², Hege Lund ${ }^{2}$, \\ Ivan W Morrison ${ }^{1}$
}

\begin{abstract}
Natural killer (NK) cells are well recognized as playing a key role in innate immune defence through cytokine production and cytotoxic activity; additionally recent studies have identified several novel NK cell functions. The ability to study NK cells in the sheep has been restricted due to a lack of specific reagents. We report the generation of a monoclonal antibody specific for ovine NKp46, a receptor which in a number of mammals is expressed exclusively in NK cells. Ovine $\mathrm{NKp} 6^{+}$cells represent a population that is distinct from $\mathrm{CD}^{+}$and $\gamma \delta^{+}$ T-cells, B-cells and cells of the monocytic lineage. The NKp46 ${ }^{+}$cells are heterogenous with respect to expression of CD2 and CD8 and most, but not all, express CD16 - characteristics consistent with NK cell populations in other species. We demonstrate that in addition to populations in peripheral blood and secondary lymphoid organs, ovine $\mathrm{NKp} 6^{+}$populations are also situated at the mucosal surfaces of the lung, gastro-intestinal tract and non-gravid uterus. Furthermore, we show that purified ovine NKp46 $6^{+}$populations cultured in IL-2 and IL-15 have cytotoxic activity that could be enhanced by ligation of NKp46 in re-directed lysis assays. Therefore we conclude that ovine $\mathrm{NKp} 6^{+}$cells represent a population that by phenotype, tissue distribution and function correspond to NK cells and that NKp46 is an activating receptor in sheep as in other species.
\end{abstract}

\section{Introduction}

Natural killer (NK) cells are lymphocytes of the innate immune system which through production of cytokines and cytotoxic activity are capable of offering an immediate response to pathogen-infected and transformed host cells [1]. NK cells recognise potential targets through a diverse repertoire of germ-line encoded activating and inhibitory receptors including members of the killer cell Ig-like receptor (KIR), Ly49, and CD94:NKG2 families and the natural cytotoxicity receptors (NCRs) NKp46, NKp30 and NKp44. Induction of NK cell function is dependent on the relative balance of signals received from activating and inhibitory receptors engaged upon interaction with target cells. Through interactions with other cells of the immune system, NK cells have also been found to regulate the development of both innate and adaptive immune responses in a variety of ways. This includes the activation/maturation of antigen-presenting cells [2], providing IFN $\gamma$ for the priming of $\mathrm{T}_{\mathrm{H}} 1 \mathrm{CD} 4^{+} \mathrm{T}$-cells [3], modulating

\footnotetext{
* Correspondence: timothy.connelley@ed.ac.uk

${ }^{1}$ The Roslin Institute, Royal (Dick) School of Veterinary Studies, University of Edinburgh, Easter Bush, Midlothian, Edinburgh, Scotland, EH25 9RG, UK Full list of author information is available at the end of the article
}

the function of $\mathrm{T}_{\text {reg }}$ cells [4] and exerting an immunoregulatory effect via the production of IL-10 [5].

Studies in a range of mammalian species have confirmed that NKp46 expression is restricted to NK cells and that it serves as the most reliable NK cell marker available [6-9]. NKp46 is a type I transmembrane glycoprotein with 2 extracellular C2-type Ig-like domains that associate via an arginine residue in the transmembrane region with the ITAM bearing molecules $\mathrm{CD} 3 \zeta$ and FceRI $\gamma[6,9,10]$. In humans, NKp46 has been shown to be a principal activating receptor against a variety of NK cell targets $[10,11]$. However, with the exceptions of the haemagglutinin of influenza virus and the haemagglutinin-neuraminidase of parainfluenza virus and Newcastle disease virus the ligands for NKp46 are currently unknown [12,13].

The generation of a bovine NKp46-specific antibody has facilitated the study of NK cells in cattle and shown that they contribute to the response against a variety of pathogens including Mycobacterium bovis, Babesia bovis and Neospora caninum [14-16]. At present there is no equivalent antibody in sheep and most previous work has been restricted to the description of NK-like
C Biomed Central

(c) 2011 Connelley et al; licensee BioMed Central Ltd. This is an Open Access article distributed under the terms of the Creative Commons Attribution License (http://creativecommons.org/licenses/by/2.0), which permits unrestricted use, distribution, and reproduction in any medium, provided the original work is properly cited. 
cytotoxicity in ovine PBMC and endometrial cell populations [17-20], although a recent publication has demonstrated that circulating $\mathrm{CD} 16^{+} / \mathrm{CD} 14^{-}$cells in ovine PBMC have the morphological and functional characteristics of NK cells [21]. In this paper we describe the generation of a monoclonal antibody specific for ovine NKp46 and show that cells expressing NKp46 have a phenotype, tissue distribution and cytotoxic function characteristic of NK cells.

\section{Materials and methods}

\section{Animals and tissue preparations}

Samples were taken from sheep of various breeds aged between 3 months and 1 year. PBMC were isolated from blood collected in EDTA by density gradient centrifugation $(900 \times g, 30 \mathrm{~min})$ over Ficoll-Paque Plus (Amersham Biosciences, Little Chalfont, UK) and washed three times in PBS/2 mM EDTA. Single-cell suspensions from spleens and lymph nodes were obtained by passing the products of dilacerated tissues through a mesh with a $50 \mu \mathrm{M}$ pore size (BD, San Jose, CA, USA). Tissue samples for immunohistochemical analysis were snap frozen in isopentane/dry ice and mounted in optimal cutting temperature (OCT) compound (Tissue-Tek, Sakura-Finitek, Zoeterwoude, The Netherlands). For samples from the lung, isolated lobes were inflated with a mixture composed of $30 \%$ sucrose in water $(\mathrm{w} / \mathrm{v})$ and OCT at a ratio of 2:1 prior to snap freezing. Tissue sections cut to $7 \mu \mathrm{m}$ thickness were mounted on poly-L-lysine coated slides and stored at $-80^{\circ} \mathrm{C}$ until use.

\section{Cloning of the ovine NKp46 gene}

The NCBI Ovis aries trace archives [22] were searched in May 2007 for sequences orthologous to bovine/ human NKp46 (GenBank AF422181/NM_004829) using the BLASTn algorithm.

Total RNA was extracted from ovine PBMC using Tri-reagent (Sigma-Aldrich, Poole, Dorset, UK) and cDNA subsequently synthesized using the Reverse Transcription System (Promega, Madison, WI, USA) with priming by the Oligo $(\mathrm{dT})_{15}$ primer, according to the manufacturer's instructions. Based on sequence data obtained from the NCBI bovine WGS archive database primers in the 5' (tcactcaccacatcctgagc) and 3' (cttcctccatgggttccac) UTR of the bovine NKp46 gene were designed and used in PCR reactions composed of $2.5 \mu \mathrm{L}$ cDNA, 25 pmol of each primer, 2.5 units of Biotaq (Bioline, London, UK), $5 \mu \mathrm{L}$ SM-0005 10× buffer (ABgene, Epsom, Surrey, UK) and water to give a final volume of $50 \mu \mathrm{L}$. The cycling conditions for these reactions were $3 \mathrm{~min}$ at $95^{\circ} \mathrm{C}, 35$ cycles of $1 \mathrm{~min}$ at $94^{\circ} \mathrm{C}$, $1 \mathrm{~min}$ at $55^{\circ} \mathrm{C}, 1 \mathrm{~min}$ at $72^{\circ} \mathrm{C}$ and a final extension period of $10 \mathrm{~min}$ at $72^{\circ} \mathrm{C}$. PCR products were purified and subcloned using the pGEM-T Easy vector system (Promega,
Madison, WI, USA) according to the manufacturer's instructions and representatives sequenced (DBS Genomics, University of Durham, UK).

DNA and predicted protein sequence analysis was performed using DNAsis Max vr2.7 software (Miraibio, Alameda, CA, USA) and the tools accessed through the InterProScan [23] and Scratch Protein Predictor [24] websites.

\section{Generation of an anti-ovine NKp46 mAb}

The extracellular region of the ovNKp46 gene was amplified from ovine PBMC by PCR using 5' (aagcttttaccaggcagaatctgag) and 3' (ggatccccagaggaaatggtcttt) primers that incorporate HindIII and BamHI restriction sites respectively in reactions composed of $2.5 \mu \mathrm{L}$ cDNA, 25 pmol of each primer, 2.5 units of Biotaq, $5 \mu \mathrm{L}$ SM-0005 $10 \times$ buffer and water to give a final volume of $50 \mu \mathrm{L}$ and run under the following conditions: $3 \mathrm{~min}$ at $95^{\circ} \mathrm{C}, 32$ cycles of $1 \mathrm{~min}$ at $94^{\circ} \mathrm{C}, 1 \mathrm{~min}$ at $58^{\circ} \mathrm{C}, 1 \mathrm{~min}$ at $72^{\circ} \mathrm{C}$ and a final extension period of $5 \mathrm{~min}$ at $72^{\circ} \mathrm{C}$. The product was purified, cloned into pGEM-T Easy, released by HindIII/ BamHI digestion and then inserted into a mammalian expression vector containing the hinge, $\mathrm{CH} 2$ and $\mathrm{CH} 3$ regions of the murine IgG2b gene (kindly provided by HC Aasheim, The Norwegian Radium Hospital, Oslo, Norway) as previously described $[7,25]$. Briefly, $40 \mu \mathrm{g}$ of construct was mixed with $160 \mu \mathrm{L}$ of Lipofectamine LTX (Invitrogen, Paisley, UK) and used to transiently transfect $293 \mathrm{~T}$ cells at $\sim 80 \%$ confluence in $162 \mathrm{~cm}^{2}$ flasks, cells were then grown in serum-free AIM-V media (Invitrogen) for four days. The secreted ovNKp46-mFc $2 \mathrm{~b}$ fusion protein was then purified on a protein G column (Amersham Biosciences) according to the manufacturer's instructions, quantified using a BCA assay (Thermo Scientific, Rockford, IL, USA) and assayed by both sodium dodecyl sulphate-polyacrylamide gel electrophoresis (SDS-PAGE) and MALDI-TOF (data not shown).

Young, female BALB/c mice were immunized with three injections: primary and secondary subcutaneous injections of $100 \mu \mathrm{g}$ and $25 \mu \mathrm{g}$ protein respectively in TitreMax Gold (TitreMax Inc, Norcross, GA, USA), and a final intraperitoneal injection of $25 \mu \mathrm{g}$ protein in PBS. Spleen cells were fused with X63 cells by conventional techniques and hybridoma clones screened by flow cytometry against P815 cells that had been permanently transfected with a pFLAG-CMV-3 expression vector (Sigma-Aldrich, Dorset, UK) containing the complete coding region of ovNKp46 gene. One hybridoma clone was sub-cloned by limiting dilution and the resulting hybridoma named EC1.1.

\section{Antibodies, flow cytometry, and fluorescent immunohistochemical analysis}

All primary monoclonal antibodies used in this study were murine, with the exception of SW73.2 which was 
produced in a rat: 36F (ovine CD2:IgG2a [26]), SW73.2 (ovine MHCII: rat IgG2b [27]), both obtained from the Moredun Research Institute, UK; 44.38 (ovine CD4: IgG2a [28]), CC126 (bovine CD11b: IgG2b [29]), both obtained from AbD Serotec, Oxford, UK; $\delta G 9$ (human perforin: IgG2b) and 36/E-cadherin (human E-cadherin: IgG2a) both from BD Biosciences (Erenbodegen, Belgium); VPM13 (ovine IgM: IgG2b - a gift from Bernadette Dutia, Centre for Infectious Diseases, University of Edinburgh), KD1 (human CD16: IgG2a - a gift from Daniela Pende, Istituto Nazionale per la Ricerca sul Cancro, Genova, Italy), CC63 (bovine CD8: IgG2a [30], CC15 (bovine WC1: IgG2a [31]) and ILA-111 (bovine CD25: IgG1 [32]). Alexa Fluor 488-conjugated murine IgG1-specific, PE-conjugated murine IgG2a-, murine IgG2b- and rat IgG- and Alexa Fluor 647-conjugated murine IgG2a-specific secondary antibodies were all obtained from Molecular Probes (Invitrogen). Isotype controls (all from AbD Serotec) were included in each experiment.

Two-colour and single colour flow cytometric analysis was performed using a FACScalibur flow cytometer with Cellquest software (BD, Franklin Lakes, USA), gated to include viable cells according to forward and side scatter parameters. For detection of intra-cellular perforin, cells were permeabilised using the Cytofix/Cytoperm kit according to the manufacturer's instructions (BD Bioscience). Optimal concentrations of all primary and secondary antibodies were determined in preliminary titration assays.

For multi-colour immunofluoresence sections were air dried prior to fixing in methanol for $10 \mathrm{~min}$ at $-20^{\circ} \mathrm{C}$. Sections were then washed twice in PBS/0.5\% Tween 80 and blocked by incubation in $10 \%$ normal goat serum in PBS/0.5\% Tween 80 for $30 \mathrm{~min}$ at room temperature. Slides were then mounted into Sequenza immunostaining units and incubated with primary antibodies at $4^{\circ} \mathrm{C}$ overnight. Following two washes in PBS/0.5\% Tween 80 slides were incubated with fluorophore conjugated secondary antibodies for $1 \mathrm{~h}$ at room temperature. After a final wash, slides were mounted in Mowiol mounting medium (Calbiochem-Novabiochem; San Diego, CA, USA), and images taken using a SPOT RT3 camera (Diagnostic Instruments, Sterling Heights, USA) mounted on an Axiovert 100 inverted microscope (Carl Zeiss; Welwyn Garden City, UK) and analysed using SPOT software (Diagnostic Instruments). All antibodies were diluted in $10 \%$ normal goat serum in PBS/0.5\% Tween 80 at the optimal concentrations as determined in preliminary titration assays.

\section{Cloning and expression of recombinant ovine IL-2}

mRNA was extracted from ConA stimulated ovine PBMC ( $\mu$ MACS kit, Miltenyi Biotec, Bergisch Gladbach,
Germany), followed by complementary DNA synthesis by SuperScriptIII reverse transcriptase and Oligo $(\mathrm{dT})_{20}$ primer (both Invitrogen). As information on the sequence in the 5' UTR of the ovine IL-2 was not available, a forward primer designed to recognize 15 nucleotides upstream of the bovine IL-2 start codon to include the translational initiation region and that also included the BamHI restriction site was used; 5'-ggatcctcaactcctgccacaatgta-3'. The reverse primer was 5'ctcgagttaagactaacagttacaaaggt- 3 ' including XhoI in the 5 ' end and recognizing the sequence 89 nucleotides into the 3'UTR of ovine IL-2. (GenBank NM_001009806.1). The ovine IL-2 sequence was amplified by PCR using PfuUltra ${ }^{\mathrm{TM}}$ (Stratagene, La Jolla, CA, USA) at $3 \mathrm{~min}$ at $94^{\circ} \mathrm{C}, 35$ cycles of $45 \mathrm{~s}$ at $94^{\circ} \mathrm{C}, 30 \mathrm{~s}$ at $60^{\circ} \mathrm{C}, 1.5 \mathrm{~min}$ at $72^{\circ} \mathrm{C}$ and a final extension period of $10 \mathrm{~min}$ at $72^{\circ} \mathrm{C}$. The obtained PCR product of $608 \mathrm{bp}$ was purified, cloned into 2.1-TOPO vector, released by BamHI/XhoI digestion and then inserted into pcDNA1 vector (Invitrogen). The correctness of the construct was verified by sequencing. Plasmid DNA was transfected into 293T cells, ovine IL-2 was harvested in RPMI medium containing 10\% FCS and the activity was determined in a proliferation assay of ConA stimulated ovine PBMC as described earlier for bovine IL-2 [33]. The supernatant containing $1 \times 10^{4} \mathrm{U}$ rOvIL- $2 / \mathrm{mL}$ was stored at $-20^{\circ} \mathrm{C}$ and used without further purification at the indicated concentration.

\section{Isolation and culture of $\mathrm{NKp} 46^{+}$cells}

$\mathrm{PBMC}$ re-suspended at $5 \times 10^{7}$ cells $/ \mathrm{mL}$ in $\mathrm{PBS} / 0.5 \%$ BSA/2 mM EDTA were incubated with EC1.1 supernatant (final dilution of 1:4, based on preliminary titration analysis) for $30 \mathrm{~min}$ at $4^{\circ} \mathrm{C}$. After two washes the cells were incubated with DynaBead pan Mouse IgG (Invitrogen) at $4 \times 10^{6}$ beads $/ \mathrm{mL}$ for $30 \mathrm{~min}$ at $4^{\circ} \mathrm{C}$ with shaking. Antibody-labelled cells were magnetically isolated using a DynaMag-15 (Invitrogen) and washed three times. Isolated cells were cultured in RPMI1640 supplemented with $100 \mathrm{U} / \mathrm{mL}$ penicillin, $100 \mu \mathrm{g} / \mathrm{mL}$ streptomycin, $292 \mu \mathrm{g} / \mathrm{mL}$ L-glutamine, $1 \mathrm{mM}$ sodium pyruvate, $50 \mu \mathrm{M}$ 2-mercaptoethanol, 10\% foetal calf serum (all from Invitrogen), $20 \mathrm{ng} / \mathrm{mL}$ recombinant human $(\mathrm{rHu})$ IL-15 (R\&D Systems, Minneapolis, USA) and rOvIL-2 at $200 \mathrm{U} / \mathrm{mL}$. Cultures were incubated at $37^{\circ} \mathrm{C}$ in $5 \% \mathrm{CO}_{2}$ for 7-8 days, with the magnetic beads removed after 48 $\mathrm{h}$ and media/cytokine supplemented every 2-3 days as required. Flow cytometric analysis on day 7-8 demonstrated that all cultures were $>93 \% \mathrm{NKp} 46^{+}$.

\section{Cytotoxicity assays}

Cytotoxic activity of cultured ovine $\mathrm{NKp} 46^{+}$cells was examined using $4 \mathrm{~h}{ }^{111} \mathrm{In}$-release assays. In brief, YAC-1, K562 and P815 target cells were re-suspended at $1 \times$ 
$10^{7} / \mathrm{mL}$ and $50 \mu \mathrm{L}$ aliquots were incubated with

${ }^{111}$ Indium oxine (Amersham Biosciences) at $37^{\circ} \mathrm{C}$ for 30 min. After six washes in RPMI 1640/5\% foetal calf serum, aliquots of $2.5 \times 10^{3}$ labelled target cells were placed into 96-well V-bottomed plates. In duplicate, two fold dilutions from $2 \times 10^{4}$ to $1.25 \times 10^{3}$ of NKp46 ${ }^{+}$ effector cells (day 7-8 of culture) were added to the labelled target cells giving effector to target cell ratios of $8: 1$ to $0.5: 1$. After incubation at $37^{\circ} \mathrm{C}$ for $4 \mathrm{~h}$ supernatant was harvested and ${ }^{111} \mathrm{In}$-release measured in a Wallac Wizard 1470 Automatic Gamma Counter (PerkinElmer, Bucks, UK). Percentage specific lysis was calculated as ((sample release-spontaneous release) $\times 100 \% /($ maximal release-spontaneous release)) and expressed as the mean of the duplicated assays. Maximal and spontaneous release were derived from triplicates of target cells incubated in $0.2 \%$ Tween 20 and RPMI1640/5\% foetal calf serum, respectively. In re-directed lysis assays P815 cells were incubated in EC1.1 supernatant or an isotype matched antibody for $30 \mathrm{~min}$ at room temperature before the final (i.e. sixth) wash removing the ${ }^{111}$ Indium oxine label.

\section{Results}

\section{The ovine NKp46 gene}

Examination of ovine sequence databases by probing with the bovine and human NKp46 nucleotide sequences only identified sequences orthologous to human NKp46 exons 4 and 5 (data not shown). To obtain complete sequence of the ovine NKp46 coding region, cDNA from ovine PBMC was amplified using PCR primers specific to the 5' and 3' UTR of the bovine NKp46 gene and the products cloned. The consensus sequence (GenBank accession number HQ433587) of these clones predicts a polypeptide product that shows $92.5 \%$ and $60.9 \%$ identity with bovine and human NKp46 respectively (Figure 1). Following removal of the predicted signal sequence (1-21aa), the mature polypeptide of 285 amino acids contains two extra-cellular Iglike domains (25-199aa and 120-212aa), an extra-cellular stem (213-254aa), a transmembrane region (255-273aa, which includes a conserved arginine) and a cytoplasmic tail (274-285aa). The predicted molecular mass of the mature unglycosylated protein is $32.2 \mathrm{kDa}$, similar to that of the bovine and human orthologues $[7,10]$. However, predicted N-glycosylation sites at Thr139 and Thr249 suggests that the molecular mass of the native protein is likely to be higher.

\section{Generation of an ovine NKp46-specific monoclonal antibody}

Mice were immunised with a fusion protein composed of the extra-cellular region of ovine NKp46 and the hinge and $\mathrm{Fc}$ region of murine IgG2b. Screening of hybridomas derived from these mice for reactivity against P815 cells transfected with an ovine NKp46-FLAG construct identified several positive hybridomas. A cloned derivative of one of these hybridomas, termed EC1.1, was obtained and found to produce an IgG1 isotype antibody that specifically recognised ovine NKp46 (Figure 2).

\section{The phenotype of ovine NKp $46^{+}$cells}

Flow cytometry analysis of samples from six animals showed that NKp46 was expressed on between 3-16\% of PBMC. Using 2-colour flow cytometry these cells were found to have a $\mathrm{CD}^{-}, \mathrm{WC1}^{-}, \mathrm{IgM}^{-}, \mathrm{MHCII}^{-}$phenotype indicating that NKp46 is expressed on a cell subset that is distinct from CD4 T-cells, $\gamma \delta \mathrm{T}$-cells, B cells and cells of the monocytic lineage (Figure 3a). CD2 expression defined two distinct NKp46 ${ }^{+}$subsets - a minor (15-26\%) $\mathrm{CD} 2^{\mathrm{hi}}$ subset and a larger $(74-85 \%) \mathrm{CD} 2^{\mathrm{lo} /-}$ population. Similarly, CD8 expression defined a CD8 ${ }^{\mathrm{lo} /}$ subset $(40-$ $55 \%)$ and a CD $8^{\text {hi }}$ subset (45-60\%). The majority (75$88 \%$ ) of the NKp $46^{+}$cells were positively stained by the monoclonal antibody KD1 which is specific for human CD16 and has been found to cross-react with the bovine orthologue of this gene and identifies populations within ovine PBMC [21,34]. Intra-cellular staining identified the presence of perforin, a protein present in cytotoxic granules of NK cells and reflecting their cytotoxic potential, in the majority of NKp $46^{+}$cells (Figure $3 \mathrm{~b}$ ). In contrast to human and murine NK cells, the ovine $\mathrm{NKp} 46^{+}$population did not express CD11b (Figure 3a).

\section{Isolation and in vitro culture of ovine $\mathrm{NKp} 46^{+}$cells}

Using EC1.1 and immunomagnetic separation NKp $46^{+}$ cells from PBMC were isolated and then cultured in vitro in media containing rOvIL-2 and rHuIL-15 to derive purified NKp $46^{+}$populations. Phenotypic analysis revealed that the cultured $\mathrm{NKp} 46^{+}$cells were uniformly $\mathrm{CD} 8^{+}$and $\mathrm{CD} 16^{\mathrm{lo} /-}$, whilst expression of CD2 defined two distinct subsets - a major $C D 2^{1 \mathrm{o} /-}$ population (77-85\%) and a minor $\mathrm{CD} 2^{\text {hi }}$ population (15-23\%) (Figure 4). CD25 was expressed on $>60 \%$ of the cells indicating that the majority of the cells in the cultured populations were activated.

\section{In vitro cultured ovine $\mathrm{NKp} 46^{+}$cells exhibit cytotoxic activity}

The cytotoxic activity of NKp $46^{+}$cultures from five animals were examined in standard $4 \mathrm{~h} \mathrm{In}^{111}$-release assays (Figure 5). The levels of cytotoxicity against YAC-1 and K562 were generally low but exhibit some inter-animal variation, with cytotoxicity at an effector to target ratio of 8:1 ranging from $\sim 3-22 \%$ between individuals. Lysis of murine Fc $\gamma$ R-expressing P815 cells was also low (ranging from $6-14 \%$ at an effector to target ratio of $8: 1$ ). However, for all five cultures pre-incubation of the P815 target cells with the EC1.1 antibody induced greatly enhanced levels of cytotoxic activity (ranging from $62-81 \%$ at an effector 
to target ratio of 8:1). This increase in lysis of P815 was not seen when pre-incubated with an isotype controlled antibody. These re-directed lysis assay results demonstrate that that all of the $\mathrm{NKp} 46^{+}$cultures had cytotoxic capability and that the NKp46 receptor functions as a cytotoxicity activating receptor in ovine NK cells.

\section{Ovine NKp $46^{+}$cell distribution in lymph nodes and mucosal surfaces}

In other species NK cells have a wide distribution, particularly in secondary lymphoid tissue and sites of potential pathogen entry. Using EC1.1 we examined the distribution of ovine NKp46 ${ }^{+}$cells in mucosal and nonmucosal lymph nodes and in the lungs, gastro-intestinal tract and non-gravid uterus of sheep.

Immunohistochemical analysis demonstrated that the distribution of $\mathrm{NKp} 46^{+}$cells in mucosal and non-mucosal lymph nodes was similar; $\mathrm{NKp} 46^{+}$cells were located in both the para-cortical and medullary areas but only rarely identified within the follicles (Figure 6a and 6b). Examination of the gastro-intestinal tract (GIT) revealed that NKp $46^{+}$cells were absent from the rumen (data not

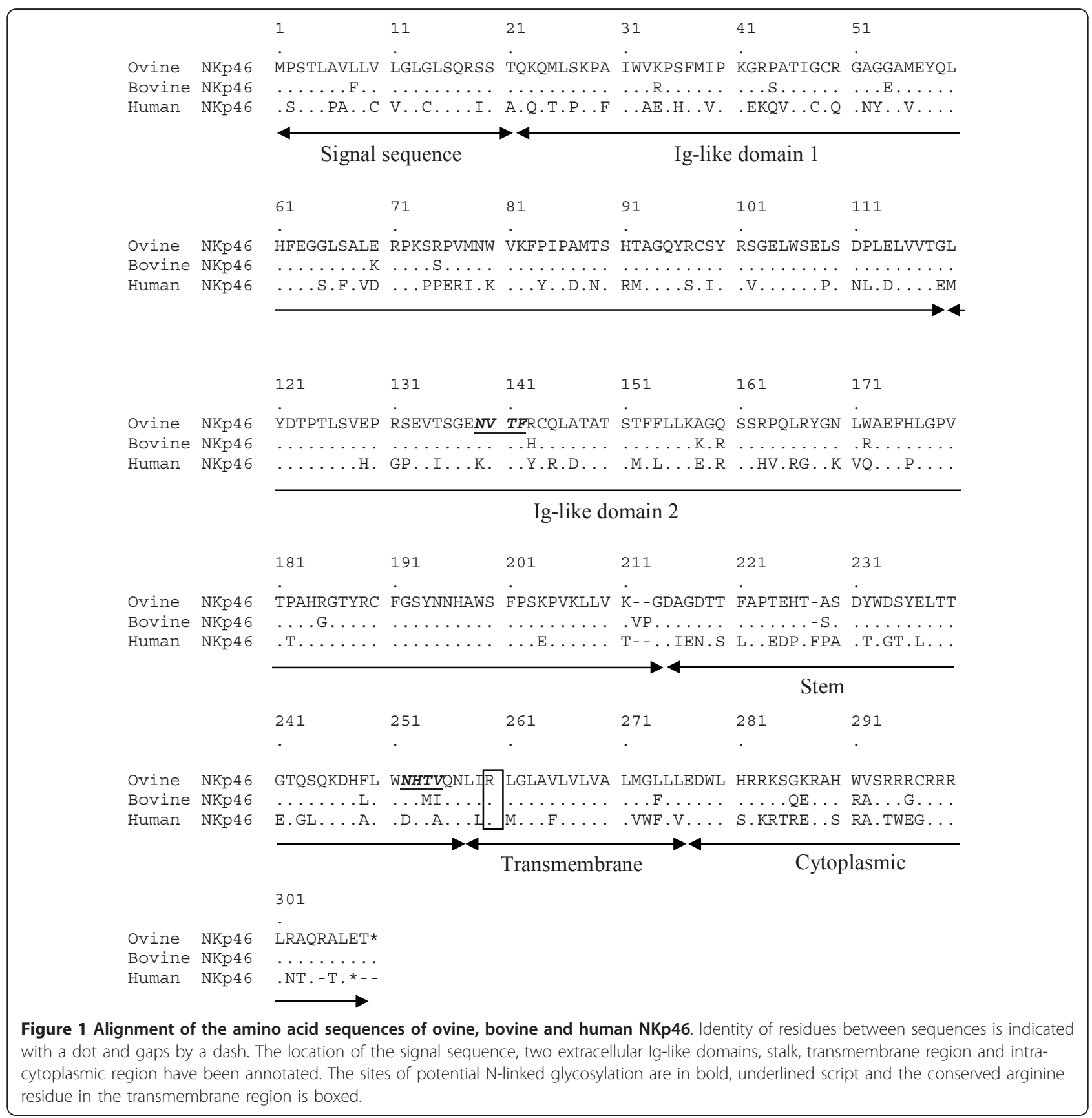




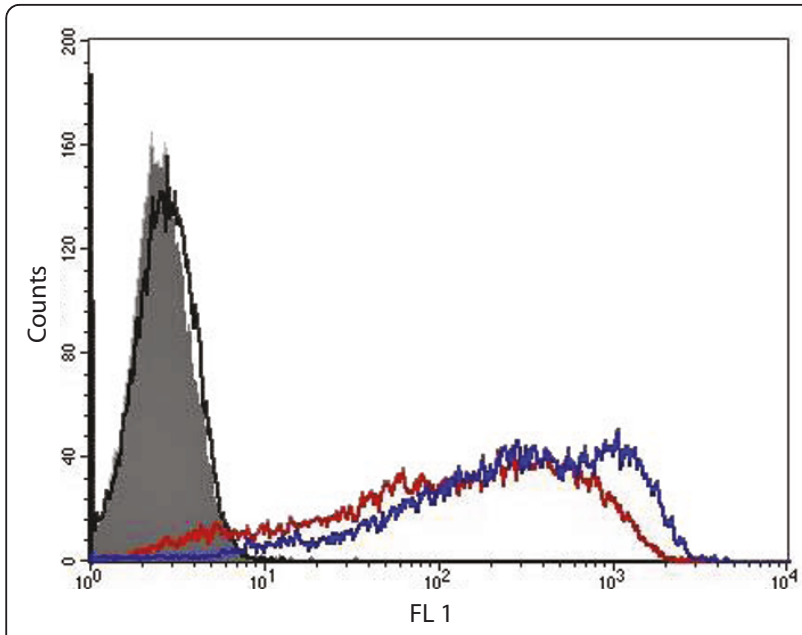

Figure 2 EC1.1 is specific for ovine NKp46. P815 cells transfected with an ovNKp46-FLAG construct are stained similarly by supernatant from EC1.1 (blue line) and a FLAG-specific antibody (red line) but not by an isotype control antibody (black line). Untransfected P815 cells are not stained by EC1.1 supernatant (solid grey).

shown) but were present sporadically throughout the lamina propria of the abomasum, duodenum, jejunum, ileum and colon, with occasional NKp $46^{+}$cells having an intra-epithelial location (e.g. Figure $6 \mathrm{c}$ and $6 \mathrm{f}$ ). Additionally it was notable that $\mathrm{NKp} 46^{+}$cells were scarce in B-cell aggregates or follicles present in the various compartments of the gut but were present in high densities in the interfollicular areas (e.g. Figure 6d and 6e). NKp46 ${ }^{+}$cells were also evident in sub-epithelial locations in the uterus (Figure $6 \mathrm{~g}$ ) and in the lung were found in the sub-epithelium of airways and also within the interstitium (Figure 6h).

NKp $46^{+}$cells in the pre-scapular and mesenteric lymph nodes constituted $2.6-6.2 \%$ and $2.2-4.2 \%$ of the mononuclear cell population respectively, and were also found at a similar frequency in the spleen (3.2-4.9\%). The phenotype of these populations were generally consistent with that of the $\mathrm{NKp} 46^{+}$cells in PBMC but tended to demonstrate a more homogenous $\mathrm{CD} 2^{\mathrm{lo}}$ and $\mathrm{CD} 8^{\text {lo }}$ expression (Figure 3c).

\section{Discussion}

Research into ovine NK cells has been impeded by a lack of specific reagents. Indeed, until recent work by Elhmouzi-Younes et al. [21], identifying the $\mathrm{CD} 16^{+} / \mathrm{CD} 14^{-}$ subset of ovine PBMC as NK cells, studies in sheep had been confined to the description of NK-like function in unfractionated lymphocyte populations from blood and uterine tissue [17-20]. In this study we report the generation of a monoclonal antibody specific for ovine NKp46, a cell surface marker specifically expressed by NK cells in a variety of species including humans, primates, mice, rat and cattle and that has been proposed as the most definitive marker for NK cells in mammals [6-9,35]. We have demonstrated that the phenotype, distribution and function of the ovine NKp46 ${ }^{+}$cells identified with this antibody correspond with those previously described for NK cells in other species.

NK cells form a phenotypically heterogenous population, with subsets of distinct phenotypes frequently associated with particular functions and/or anatomical location [36]. Comprehensive inter-species comparisons of NK cell phenotype is precluded by differences in NK cell markers expressed in individual species [35]. However the phenotype of ovine NKp46 $6^{+}$cells in PBMC and secondary lymphoid tissues (spleen, mucosal and nonmucosal lymph nodes) was consistent with that of NK cells in other species in several respects. Firstly, NKp $46^{+}$ cells formed subsets that were distinct from CD $4^{+}$ T-cell, $\gamma \delta^{+} \mathrm{T}$-cell, B-cell and monocytic populations [7,9]. Secondly, approximately $80-90 \%$ of the $\mathrm{NKp} 46^{+}$cells expressed CD16 (FcrRIII) - the receptor that mediates antibody-dependent cell-mediated cytotoxicity by NK cells - comparable to levels observed in the equivalent populations in cattle and in human PBMC $[34,36]$. These data indicate that the $\mathrm{CD} 16^{+} / \mathrm{CD} 14^{-}$phenotype used recently by Elhmouzi-Younes et al. [21] to define peripheral ovine NK cells successfully identifies most but not all NKp46 $6^{+}$cells and could be equally well applied to NK cells in secondary lymphoid tissues. Thirdly, ovine $\mathrm{NKp} 46^{+}$cells expressed perforin, an integral part of the granule exocytosis mediated cytotoxicity machinery used by NK cells for target cell lysis. The constitutive expression of molecules involved in this cytotoxicity pathway is characteristic of NK cells with lytic function and permits them to function without the requirement for induced expression that is seen in $\mathrm{CD} 8^{+}$ T-cells $[37,38]$. Fourthly, as seen in humans and cattle NK cells, ovine NKp $46^{+}$cells exhibited varied levels of $\mathrm{CD} 2$ and $\mathrm{CD} 8$ expression, such that in blood CD2 $2^{-/ 10}$ and $\mathrm{CD} 2^{\mathrm{hi}}$ as well as $\mathrm{CD} 8^{-/ \mathrm{lo}}$ and $\mathrm{CD} 8^{\mathrm{hi}}$ subsets could be distinguished, whilst in secondary lymphoid tissues a more homogenous $\mathrm{CD} 2{ }^{\mathrm{lo}} / \mathrm{CD} 8^{\mathrm{lo}}$ population was observed $[7,39]$. Of note, ovine NKp $46^{+}$cells did not express CD11b, a molecule expressed on both human and murine NK cells; a previous report has described bovine NK cells as also having a CD11 $\mathrm{b}^{-}$phenotype, suggesting this may be a general characteristic of ruminant NK cells [40].

In this study we have demonstrated that ovine $\mathrm{NKp} 46^{+}$ cells isolated from PBMC and cultured in the presence of rOvIL-2/rHuIL-15 exhibited cytotoxicity, one of the "classic" NK cell functions. In direct lysis assays against the xenogenic target cell lines K562 and YAC-1 the levels of cytotoxicity achieved by $\mathrm{NKp} 46^{+}$cells varied between individual sheep, similar to observations made in cattle [7]. However, in redirected lysis assays using the antiNKp46 antibody, NKp $46^{+}$cells from all individuals 
A
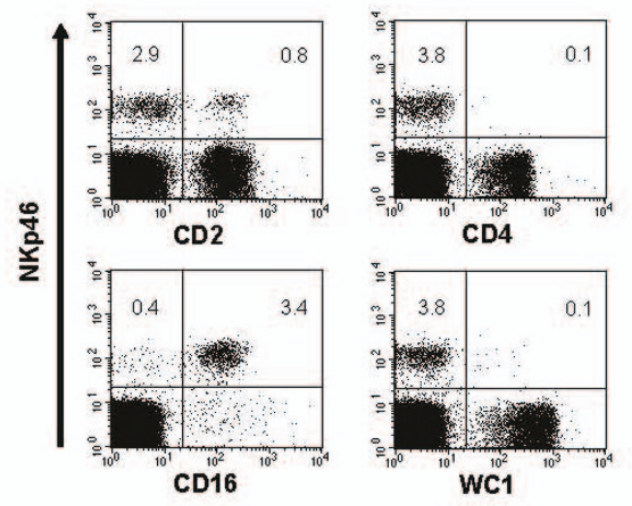

wc1

B

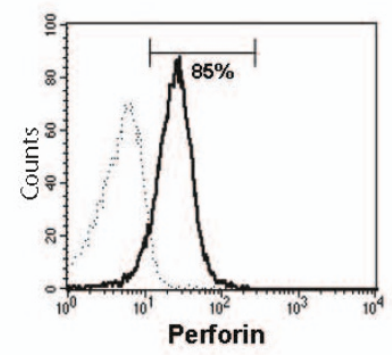

C

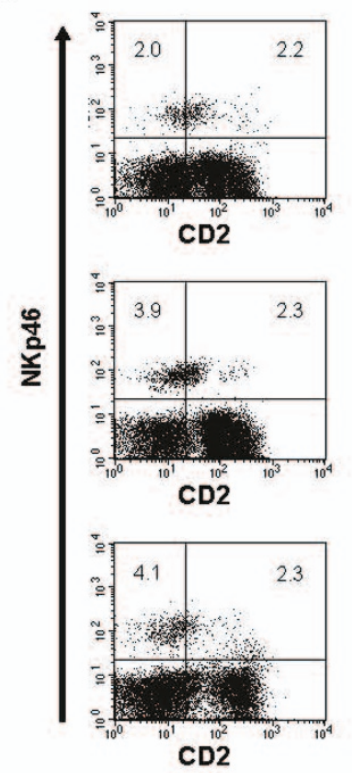

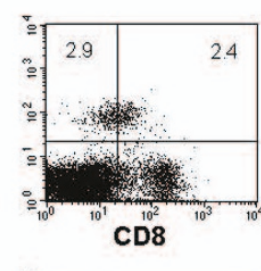
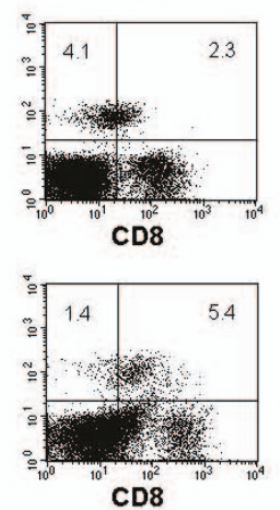
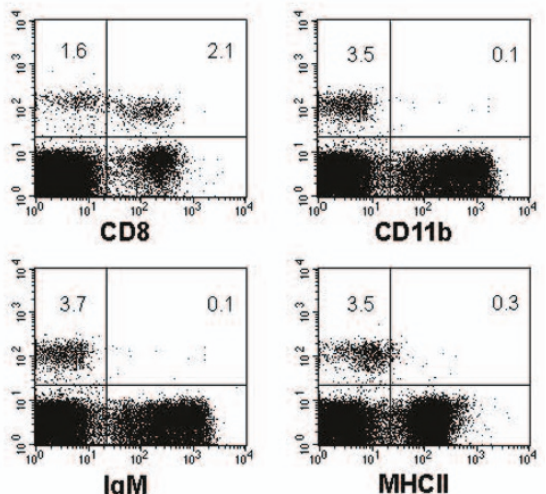

MHCII

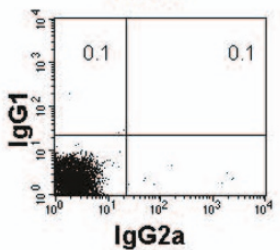

\section{Mesenteric LN}

Pre scapular LN

Spleen

Figure 3 Analysis of the phenotype of ovine $\mathrm{NKp}^{4} 6^{+}$populations. (A)Two-colour flow cytometry analysis of ovine PBMC co-stained with EC1.1 and a selection of monoclonal antibodies against CD2, CD4, CD8, CD11b, CD16, WC1, IgM and MHCII. WC1 and IgM are surface molecules expressed by subsets of $\gamma \delta$ T-cells and B-cells respectively. (B) Perforin expression by NKp46 ${ }^{+}$PBMC. Cells expressing NKp46 were stained with anti-perforin monoclonal antibody (solid line) or an isotype control (broken line). (C) Two-colour flow cytometry analysis of mesenteric and prescapular lymph nodes and the spleen cell populations co-stained with EC1.1 and monoclonal antibodies against CD2 and CD8. The results shown are representative of the results obtained from a minimum of five animals. 

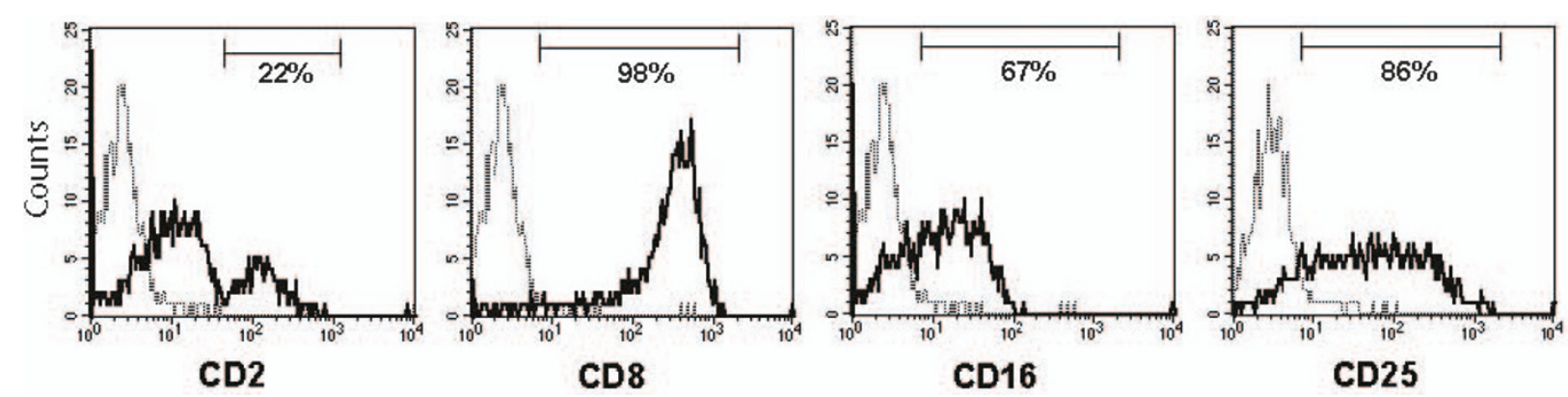

Figure 4 Phenotype of cultured $\mathrm{NKp} 46^{+}$populations. Ovine $\mathrm{NKp} 46^{+}$populations after $7-8$ days of in vitro culture were stained with monoclonal antibodies against CD2, CD8, CD16 and CD25 (solid lines) or isotype controls (broken lines). Results are shown from one culture that was representative of those derived from five animals.

showed high levels of killing, demonstrating that i) all of the ovine $\mathrm{NKp} 46^{+}$cultures had the capacity to mediate cytotoxicity, with differences of cytotoxicity observed in direct lysis assays therefore likely to represent variation in the repertoire of expressed inhibitory/activatory receptors by $\mathrm{NKp} 46^{+}$cells from individual sheep and ii) as reported in other species engagement of the NKp46 receptor is a potent trigger for NK cell activity $[6,7,9]$. During culture, NKp $46^{+}$cells were non-adherent and became enlarged with prominent lamellopodia (data not shown). These morphological characteristics and the predominantly $\mathrm{CD} 22^{\mathrm{lo}} / \mathrm{CD} 8^{\mathrm{hi}} / \mathrm{CD} 25^{+}$phenotype, resembled those described for ovine $\mathrm{CD} 16^{+} / \mathrm{CD} 14^{-}$cells and bovine $\mathrm{NKp} 46^{+}$cells [21] and provide further evidence that ovine $\mathrm{NKp} 46^{+}$and $\mathrm{CD} 16^{+} / \mathrm{CD} 14^{-}$cells represent overlapping populations. Interestingly we noted that cultured NKp $46^{+}$cells were $\mathrm{CD} 16^{\mathrm{lo}}$, suggesting downregulation of CD16 during activation, in contrast to the upregulation seen in cattle [34]. This downregulation may contribute to the low level of cytotoxicity reported by ElhmouziYounes et al. [21] in re-directed cytotoxicity assays using the anti-CD16 antibody, although data from similar studies in cattle suggest that NKp46 engagement induces higher cytotoxicity than that of CD16 [34].

NK cells are widely distributed throughout both lymphoid and non-lymphoid tissues [41]. Consistent with this, we identified ovine $\mathrm{NKp} 46^{+}$populations in blood, lymph nodes, spleen and at the mucosal surfaces of the lung, gastro-intestinal tract (GIT) and uterus. Within lymph nodes ovine NKp $46^{+}$cell distribution corresponded with that described for NK cells in bovine, murine and human lymph nodes - with scattered cells present in the paracortical and medullary regions but largely absent from the follicles $[3,8,34,42]$. A principal role of lymph node NK cells is to regulate adaptive and innate immunity through participating in a reciprocal activation dialogue with dendritic cells and via the provision of IFN $\gamma$ for $\mathrm{T}_{\mathrm{H}} 1$ priming of CD4 ${ }^{+} \mathrm{T}$-cells $[3,43,44]$. Paracortical NK cells are in close proximity to DC and T-cells and optimally situated for this function. In contrast it is thought that medullary NK cells represent cells exiting the lymph nodes and are therefore of limited functional relevance [43]. The distribution of NK cells at the mucosal surfaces has not been described previously in ruminants. NKp $46^{+}$cells were found in the mucosa of all compartments of the ovine GIT examined but were not detected in the rumen. Absence of NKp $46^{+}$ cells in the rumen probably reflects the distinct physiological role of the ruminant fore-stomachs (rumen, omasum and reticulum) which have a stratified epithelial lining and act as a fermentation system. In the rest of the ovine GIT $\mathrm{NKp} 46^{+}$cells were present at high density adjacent to lymphoid aggregates (such as Peyer's patches) and found at a lower density throughout the lamina propria with occasional cells present in an intra-epithelial position. This distribution is similar to that described in mice and humans $[45,46]$ and reflects a functional role of NK cells in interacting with antigen-presenting cells, which are also found predominantly in the lamina propria. NKp $46^{+}$cells were also found in sub-epithelial locations in the non-gravid uterus and in both sub-epithelial locations and within the parenchyma of the lungs. Mucosal surfaces, especially those of the gut and lung, are major portals for pathogen entry. NK cells in the lung have been shown to contribute to protection against a wide range of pulmonary pathogens by production of IFN $\gamma$ and/or cytotoxic activity [47]. In contrast, recent evidence from human and murine studies suggest that the majority of NK cell in the GIT lack IFN $\gamma$ and cytotoxic function but contribute to mucosal immunity against pathogens by production of IL-22 [45,46]. Although uterine NK cells are also considered to have an anti-pathogenic function, evidence for this is limited [48], with most uterine NK cell studies focusing on their functional role in regulating placental development during pregnancy [49]. However, uterine NK cell biology is complex and the exact role(s) of uterine NK cells remains controversial $[48,49]$. Futhermore, the significant differences between the reproductive biology of ruminants (cotyledonary-epitheliochorial placental structure) and rodents/ 
801

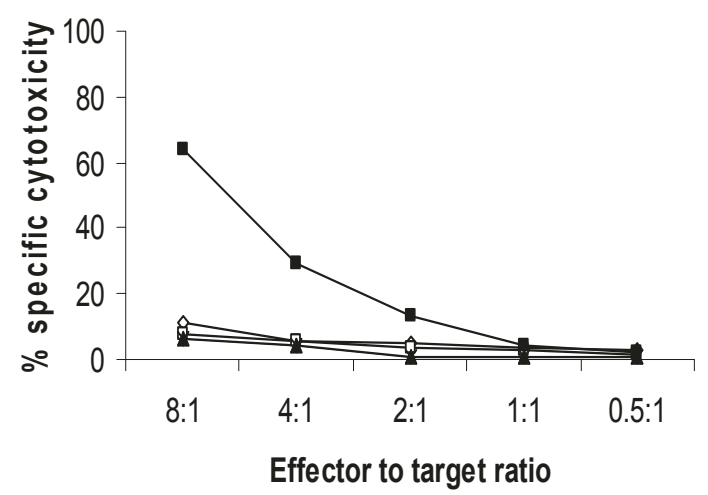

802

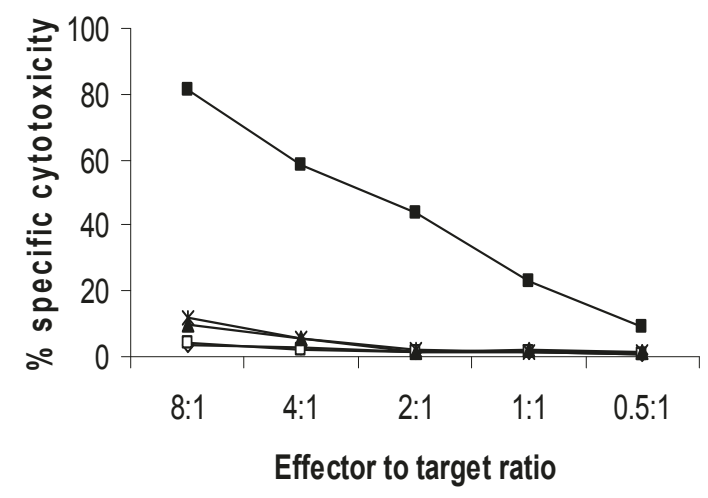

803

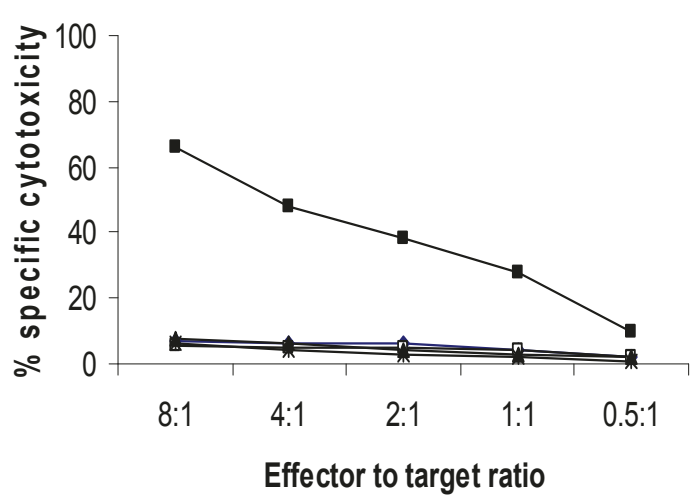

805

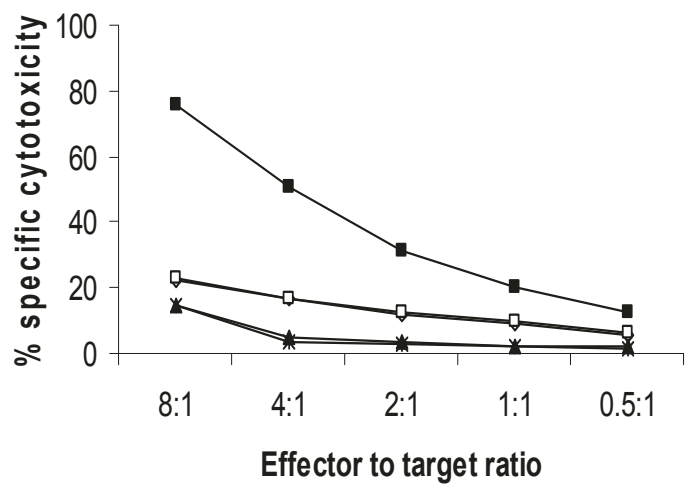

806
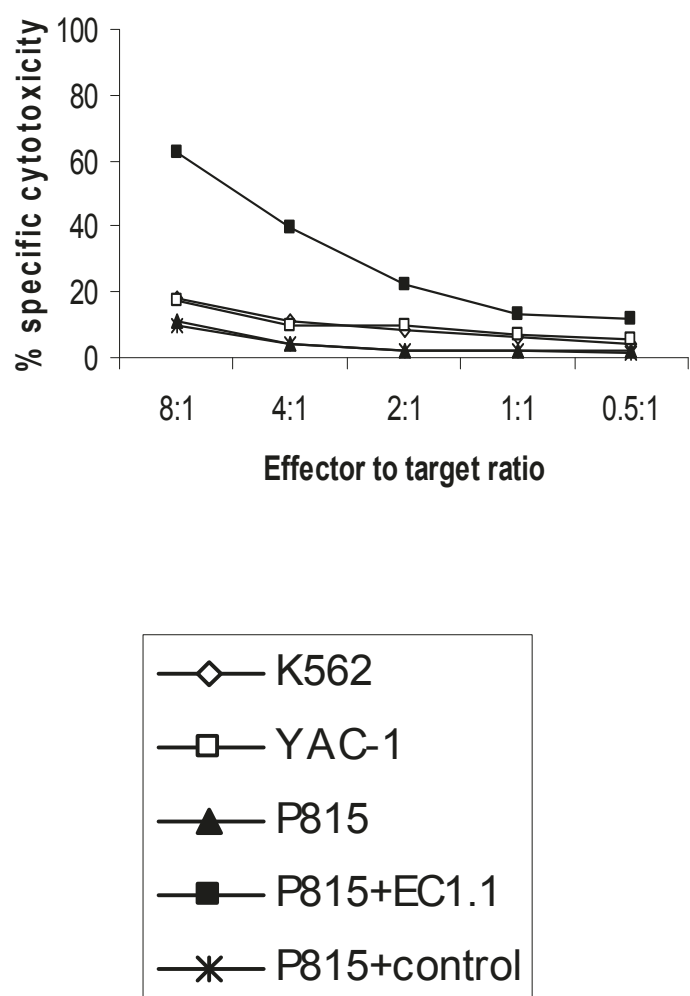

Figure 5 Cultured Ovine NKp46 ${ }^{+}$cells exhibited cytotoxic activity. Cytotoxicity of NKp $46^{+}$cultures from five animals as determined in 4 h${ }^{111}$ In release assays. Lysis of the xenogenic NK-sensitive cells lines K562 and YAC1 exhibited inter-animal variation, with lysis ranging from approximately $3-22 \%$ at effector to target ratios of 8:1. Direct lysis of P815 cells ( $F\left(y R^{+}\right)$was low (6-14\% at effector to target ratios of 8:1), but in redirected cytotoxicity assays pre-incubation with anti-NKp46 antibody (EC1.1) dramatically increased cytotoxic activity (62-81\% at effector to target ratios of 8:1) of all NKp46 ${ }^{+}$cultures. Pre-incubation with an isotype control antibody did not elevate cytotoxicity above that seen in the absence of antibody. 


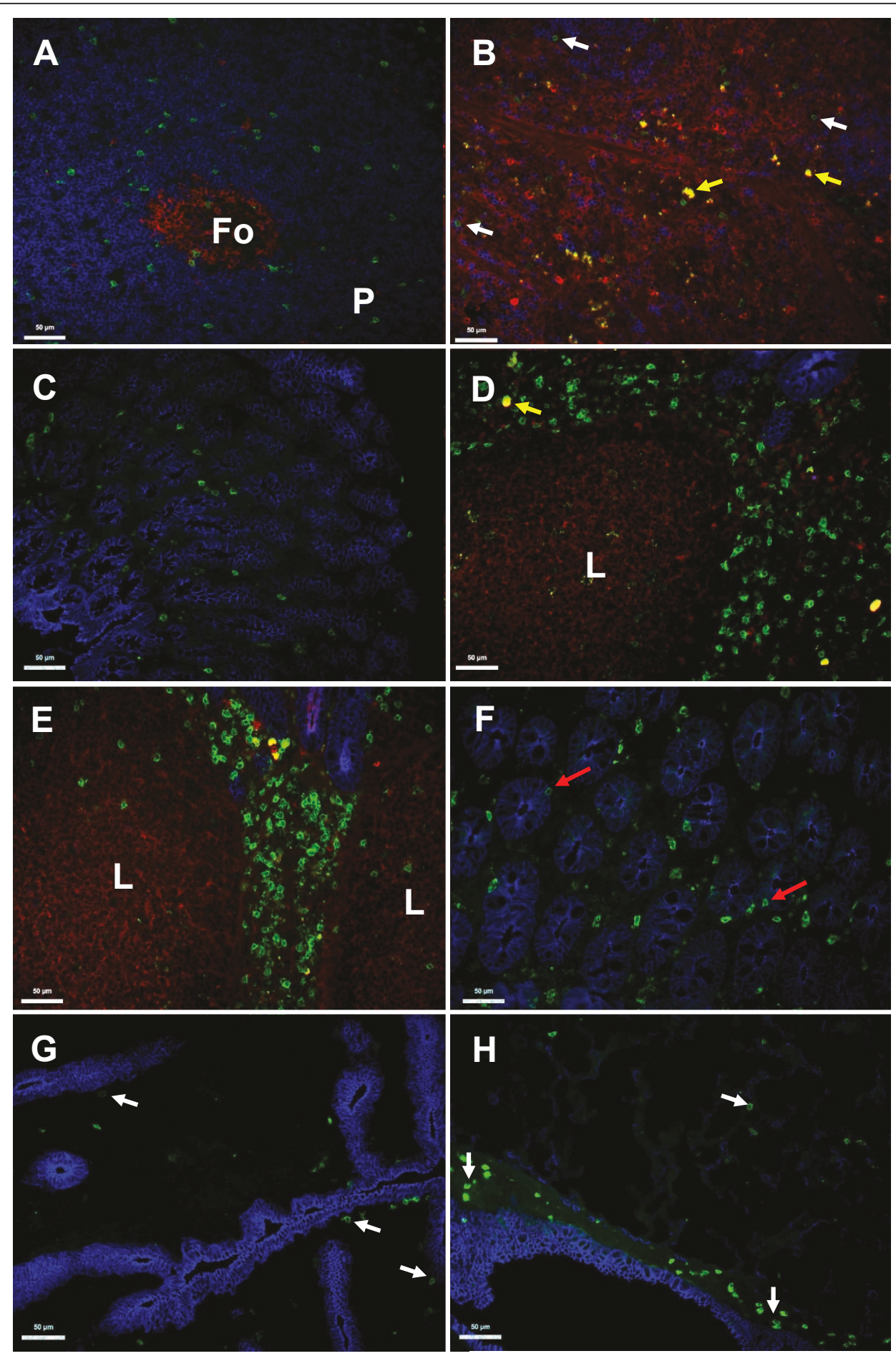

Figure 6 Distribution of ovine NKp46 ${ }^{+}$cells in lymph nodes and mucosal surfaces. Sections from ovine pre-scapular lymph node (A cortex and B - medullary zone), abomasum (C), duodenum (D), ileum (E), colon (F), uterus (G) and lung (H). NKp46 ${ }^{+}$cells: green; B-cells (lgM ${ }^{+}$) red; $C D 4^{+}$T-cells blue in panel A and B; Epithelial cells (E-cadherin ${ }^{+}$) blue in parts $\mathrm{C}-\mathrm{H}$. White arrows: individual NKp46 ${ }^{+}$cells. Red arrows: putative intra-epithelial NKp46 ${ }^{+}$cells. "Fo": follicle and "P": paracortex. "L": Iymphocytic aggregate. Isotype matched controls demonstrated diffuse and dull background fluorescence in both the red and green channels (data not shown), however this could easily be distinguished by character and/or intensity from the bright cell-surface staining seen with the NKp46 and IgM-specific antibodies. Autofluorescent artifacts such as those demonstrated by the yellow arrows (e.g. in C and D) were not uncommon in the tissues examined. A scale for each of the figure parts is given. Images are taken from tissues that were representative of samples taken from a minimum of three animals as determined by preliminary single colour immuncytochemistry analysis. 
primates (discoid-haemochorial placentae) suggest that functional equivalence of uterine NK cells in these species can not be totally assumed.

In conclusion, we have provided a preliminary characterisation of ovine $\mathrm{NKp} 46^{+}$cells and shown them to have a phenotype, distribution and function similar to those of NK cells in other species. Recently there have been rapid advances in understanding of NK cell biology, including the identification of novel functions $[5,45,46]$ and evidence of "memory-like" NK cell subsets $[50,51]$. The availability of a monoclonal antibody specific for ovine NK cells will hopefully facilitate further studies both of the comparative biology of these cells in different species and also to investigate their role in immunity to important production diseases of sheep.

\section{Acknowledgements}

We would like to thank Gordon Goodall and Neil Maclntyre at the Veterinary Pathology Unit of the Royal (Dick) School of Veterinary Medicine for their help with tissue preparation and the farm staff at the Roslin Institute for care of the animals. T Connelley was funded by a grant awarded through the VTRI initiative of the UK Department for Food and Rural Affairs and the Scottish Higher Education Funding Council.

\section{Author details}

${ }^{1}$ The Roslin Institute, Royal (Dick) School of Veterinary Studies, University of Edinburgh, Easter Bush, Midlothian, Edinburgh, Scotland, EH25 9RG, UK. ${ }^{2}$ Department of Food Safety and Infection Biology, Norwegian School of Veterinary Science, P.O. Box 8146, Dep, N-0033 Oslo, Norway. ${ }^{3}$ Reproductive Biology, The Queens Medical Research Institute, University of Edinburgh, Edinburgh, Scotland, EH16 4TJ, UK

\section{Authors' contributions}

TC - design of study, laboratory work and preparation of manuscript; AK design of study and editing manuscript; AP - production of recombinant protein; NM - generation of the mono-clonal antibody; JB - fluorescent immunohistochemistry; $\mathrm{HL}$ - production the recombinant ovine IL2; WIM design of study and editing manuscript. All authors read and approved the final manuscript.

\section{Competing interests}

The authors declare that they have no competing interests.

Received: 2 November 2010 Accepted: 23 February 2011 Published: 23 February 2011

\section{References}

1. Yokoyama WM, Kim S, French AR: The dynamic life of natural killer cells. Annu Rev Immunol 2004, 22:405-429.

2. Gerosa F, Baldani-Guerra B, Nisii C, Marchesini V, Carra G, Trinchieri G: Reciprocal activating interaction between natural killer cells and dendritic cells. J Exp Med 2002, 195:327-333.

3. Martin-Fontecha A, Thomsen LL, Brett S, Gerard C, Lipp M, Lanzavecchia A, Sallusto F: Induced recruitment of NK cells to lymph nodes provides IFNgamma for $\mathrm{T}(\mathrm{H}) 1$ priming. Nat Immunol 2004, 5:1260-1265.

4. Roy S, Barnes PF, Garg A, Wu S, Cosman D, Vankayalapati R: NK cells lyse T regulatory cells that expand in response to an intracellular pathogen. $\mathrm{J}$ Immunol 2008, 180:1729-1736.

5. Maroof A, Beattie L, Zubairi S, Svensson M, Stager S, Kaye PM: Posttranscriptional regulation of 1110 gene expression allows natural killer cells to express immunoregulatory function. Immunity 2008, 29:295-305.

6. Sivori S, Vitale M, Morelli L, Sanseverino L, Augugliaro R, Bottino C, Moretta L, Moretta A: p46, a novel natural killer cell-specific surface molecule that mediates cell activation. J Exp Med 1997, 186:1129-1136.
7. Storset AK, Kulberg S, Berg I, Boysen P, Hope JC, Dissen E: NKp46 defines a subset of bovine leukocytes with natural killer cell characteristics. Eur J Immunol 2004, 34:669-676.

8. Walzer T, Blery M, Chaix J, Fuseri N, Chasson L, Robbins SH, Jaeger S, Andre P, Gauthier L, Daniel L, Chemin K, Morel Y, Dalod M, Imbert J, Pierres M, Moretta A, Romagne F, Vivier E: Identification, activation, and selective in vivo ablation of mouse NK cells via NKp46. Proc Natl Acad Sci USA 2007, 104:3384-3389.

9. Westgaard IH, Berg SF, Vaage JT, Wang LL, Yokoyama WM, Dissen E, Fossum S: Rat NKp46 activates natural killer cell cytotoxicity and is associated with FcepsilonRlgamma and CD3zeta. J Leukoc Biol 2004, 76:1200-1206.

10. Pessino A, Sivori S, Bottino C, Malaspina A, Morelli L, Moretta L, Biassoni R, Moretta A: Molecular cloning of NKp46: a novel member of the immunoglobulin superfamily involved in triggering of natural cytotoxicity. J Exp Med 1998, 188:953-960

11. Sivori S, Pende D, Bottino C, Marcenaro E, Pessino A, Biassoni R, Moretta L, Moretta A: NKp46 is the major triggering receptor involved in the natural cytotoxicity of fresh or cultured human NK cells. Correlation between surface density of NKp46 and natural cytotoxicity against autologous, allogeneic or xenogeneic target cells. Eur J Immunol 1999, 29:1656-1666.

12. Jarahian M, Watzl C, Fournier P, Arnold A, Djandji D, Zahedi S, Cerwenka A, Paschen A, Schirrmacher V, Momburg F: Activation of natural killer cells by newcastle disease virus hemagglutinin-neuraminidase. J Virol 2009, 83:8108-8121.

13. Mandelboim O, Lieberman N, Lev M, Paul L, Arnon TI, Bushkin Y, Davis DM, Strominger JL, Yewdell JW, Porgador A: Recognition of haemagglutinins on virus-infected cells by NKp46 activates lysis by human NK cells. Nature 2001, 409:1055-1060.

14. Boysen P, Klevar S, Olsen I, Storset AK: The protozoan Neospora caninum directly triggers bovine NK cells to produce gamma interferon and to kill infected fibroblasts. Infect Immun 2006, 74:953-960.

15. Denis M, Keen DL, Parlane NA, Storset AK, Buddle BM: Bovine natural killer cells restrict the replication of Mycobacterium bovis in bovine macrophages and enhance IL-12 release by infected macrophages. Tuberculosis (Edinb) 2007, 87:53-62.

16. Goff WL, Storset AK, Johnson WC, Brown WC: Bovine splenic NK cells synthesize IFN-gamma in response to IL-12-containing supernatants from Babesia bovis-exposed monocyte cultures. Parasite Immunol 2006, 28:221-228.

17. Liu WJ, Hansen PJ: Effect of the progesterone-induced serpin-like proteins of the sheep endometrium on natural-killer cell activity in sheep and mice. Biol Reprod 1993, 49:1008-1014.

18. Segerson EC, Beetham PK: High-density ovine endometrial cells exhibit natural killer activity during early pregnancy. Theriogenology 2000 54:1207-1214.

19. Tekin S, Hansen PJ: Natural killer-like cells in the sheep: functional characterization and regulation by pregnancy-associated proteins. Exp Biol Med 2002, 227:803-811.

20. Tuo W, Ott TL, Bazer FW: Natural killer cell activity of lymphocytes exposed to ovine, type I, trophoblast interferon. Am J Reprod Immunol $1993,29 \cdot 26-34$

21. Elhmouzi-Younes J, Boysen P, Pende D, Storset AK, Le Vern Y, Laurent F, Drouet F: Ovine CD16+/CD14- blood lymphocytes present all the major characteristics of natural killer cells. Vet Res 2010, 41:4.

22. NCBlblast. [http://blast.ncbi.nlm.nih.gov/Blast.cgi].

23. InterProScan. [http://www.ebi.ac.uk/Tools/InterProScan]

24. ScratchProteinPredictor. [http://www.ics.uci.edu/ baldig/scratch]

25. Aasheim HC, Munthe E, Funderud S, Smeland EB, Beiske K, Logtenberg T: A splice variant of human ephrin-A4 encodes a soluble molecule that is secreted by activated human B lymphocytes. Blood 2000, 95:221-230.

26. Mackay CR, Hein WR, Brown MH, Matzinger P: Unusual expression of CD2 in sheep: implications for T cell interactions. Eur J Immunol 1988, 18:1681-1688.

27. Hopkins J, Dutia BM, McConnell I: Monoclonal antibodies to sheep lymphocytes. I. Identification of MHC class II molecules on lymphoid tissue and changes in the level of class II expression on lymph-borne cells following antigen stimulation in vivo. Immunology 1986, 59:433-438.

28. Maddox JF, Mackay CR, Brandon MR: Surface antigens, SBU-T4 and SBUT8, of sheep T lymphocyte subsets defined by monoclonal antibodies. Immunology 1985, 55:739-748. 
29. Naessens J, Howard CJ: Leukocyte antigens of cattle and sheep. Monoclonal antibodies submitted to the Second Workshop. Vet Immunol Immunopathol 1993, 39:5-10.

30. MacHugh ND, Sopp P: Individual antigens of cattle. Bovine CD8 (BoCD8). Vet Immunol Immunopathol 1991, 27:65-69.

31. Howard CJ, Sopp P, Parsons KR, Finch J: In vivo depletion of BoT4 (CD4) and of non-T4/T8 lymphocyte subsets in cattle with monoclonal antibodies. Eur J Immunol 1989, 19:757-764.

32. Naessens J, Sileghem M, MacHugh N, Park YH, Davis WC, Toye P: Selection of BoCD25 monoclonal antibodies by screening mouse $L$ cells transfected with the bovine p55-interleukin-2 (IL-2) receptor gene. Immunology 1992, 76:305-309.

33. Boysen P, Olsen I, Berg I, Kulberg S, Johansen GM, Storset AK: Bovine CD2-/ NKp46+ cells are fully functional natural killer cells with a high activation status. BMC Immunol 2006, 7:10.

34. Boysen P, Gunnes G, Pende D, Valheim M, Storset AK: Natural killer cells in lymph nodes of healthy calves express CD16 and show both cytotoxic and cytokine-producing properties. Dev Comp Immunol 2008, 32:773-783.

35. Walzer T, Jaeger S, Chaix J, Vivier E: Natural killer cells: from CD3(-)NKp46 (+) to post-genomics meta-analyses. Curr Opin Immunol 2007, 19:365-372.

36. Cooper MA, Fehniger TA, Caligiuri MA: The biology of human natural killer-cell subsets. Trends Immunol 2001, 22:633-640.

37. Jacobs R, Hintzen G, Kemper A, Beul K, Kempf S, Behrens G, Sykora KW, Schmidt RE: CD56bright cells differ in their KIR repertoire and cytotoxic features from CD56dim NK cells. Eur J Immunol 2001, 31:3121-3127.

38. Obata-Onai A, Hashimoto S, Onai N, Kurachi M, Nagai S, Shizuno K, Nagahata T, Matsushima K: Comprehensive gene expression analysis of human NK cells and CD8(+) T lymphocytes. Int Immunol 2002, 14:1085-1098.

39. Lima M, Teixeira MA, Queiros ML, Leite M, Santos AH, Justica B, Orfao A: Immunophenotypic characterization of normal blood CD56+lo versus CD56+hi NK-cell subsets and its impact on the understanding of their tissue distribution and functional properties. Blood Cells Mol Dis 2001, 27:731-743.

40. Endsley JJ, Endsley MA, Estes DM: Bovine natural killer cells acquire cytotoxic/effector activity following activation with IL-12/15 and reduce Mycobacterium bovis BCG in infected macrophages. J Leukoc Biol 2006, 79:71-79.

41. Gregoire C, Chasson L, Luci C, Tomasello E, Geissmann F, Vivier E, Walzer T: The trafficking of natural killer cells. Immunol Rev 2007, 220:169-182.

42. Fehniger TA, Cooper MA, Nuovo GJ, Cella M, Facchetti F, Colonna M, Caligiuri MA: CD56bright natural killer cells are present in human lymph nodes and are activated by T cell-derived IL-2: a potential new link between adaptive and innate immunity. Blood 2003, 101:3052-3057.

43. Bajenoff M, Breart B, Huang AY, Qi H, Cazareth J, Braud VM, Germain RN, Glaichenhaus N: Natural killer cell behavior in lymph nodes revealed by static and real-time imaging. J Exp Med 2006, 203:619-631.

44. Degli-Esposti MA, Smyth MJ: Close encounters of different kinds: dendritic cells and NK cells take centre stage. Nat Rev Immunol 2005, 5:112-124.

45. Cella M, Fuchs A, Vermi W, Facchetti F, Otero K, Lennerz JK, Doherty JM, Mills JC, Colonna M: A human natural killer cell subset provides an innate source of IL-22 for mucosal immunity. Nature 2009, 457:722-725.

46. Satoh-Takayama N, Vosshenrich CA, Lesjean-Pottier S, Sawa S, Lochner M, Rattis F, Mention JJ, Thiam K, Cerf-Bensussan N, Mandelboim O, Eberl G, Di Santo JP: Microbial flora drives interleukin 22 production in intestinal NKp46+ cells that provide innate mucosal immune defense. Immunity 2008, 29:958-970.

47. Culley FJ: Natural killer cells in infection and inflammation of the lung. Immunology 2009, 128:151-163.

48. Bulmer JN, Lash GE: Human uterine natural killer cells: a reappraisal. $\mathrm{Mol}$ Immunol 2005, 42:511-521.

49. Manaster I, Mandelboim O: The unique properties of uterine NK cells. Am J Reprod Immunol 2010, 63:434-444

50. Cooper MA, Elliott JM, Keyel PA, Yang L, Carrero JA, Yokoyama WM: Cytokine-induced memory-like natural killer cells. Proc Natl Acad Sci USA 2009, 106:1915-1919.

51. Sun JC, Beilke JN, Lanier LL: Adaptive immune features of natural killer cells. Nature 2009, 457:557-561.

doi:10.1186/1297-9716-42-37

Cite this article as: Connelley et al:: NKp46 defines ovine cells that have characteristics corresponding to NK cells. Veterinary Research 2011 42:37.

\section{Submit your next manuscript to BioMed Central and take full advantage of:}

- Convenient online submission

- Thorough peer review

- No space constraints or color figure charges

- Immediate publication on acceptance

- Inclusion in PubMed, CAS, Scopus and Google Scholar

- Research which is freely available for redistribution 